\title{
Role of Hormones in the Regulation of RACK1 Expression as a Signaling Checkpoint in Immunosenescence
}

\author{
Marco Racchi ${ }^{1, *}\left(\mathbb{D}\right.$, Erica Buoso ${ }^{1}$, Melania Ronfani ${ }^{1}$, Melania M. Serafini ${ }^{1,2}$, \\ Marilisa Galasso ${ }^{1}$, Cristina Lanni ${ }^{1}$ and Emanuela Corsini ${ }^{3}$ \\ 1 Department of Drug Sciences, Università degli Studi di Pavia, Viale Taramelli 12/14, 27100 Pavia, Italy; \\ buoso.erica@gmail.com (E.B.); melania.ronfani01@universitadipavia.it (M.R.); \\ melania.serafini@iusspavia.it (M.M.S.); galassomarilisa@gmail.com (M.G.); cristina.lanni@unipv.it (C.L.) \\ 2 Scuola Universitaria Superiore IUSS Pavia, Piazza della Vittoria 15, 27100 Pavia, Italy \\ 3 Laboratory of Toxicology, Department of Environmental Science and Policy, Università degli Studi di \\ Milano, Via Balzaretti 9, 20133 Milano, Italy; emanuela.corsini@unimi.it \\ * Correspondence: racchi@unipv.it; Tel.: +39-038-298-7738
}

Received: 9 May 2017; Accepted: 30 June 2017; Published: 6 July 2017

\begin{abstract}
Immunosenescence defines the decline in immune function that occurs with aging. This has been associated, at least in part, with defective cellular signaling via protein kinase C (PKC) signal transduction pathways. Our data suggest reduced PKC activation and consequently reduced response to lipopolysaccharide (LPS) stimulation and cytokine release. The lack of PKC activation seems to be dependent on the reduced expression of the receptor for activated C kinase 1 (RACK1), a scaffolding protein involved in multiple signal transduction cascades. The defective expression of RACK1 may be dependent on age-related alteration of the balance between the adrenal hormones cortisol and dehydroepiandrosterone (DHEA). DHEA levels reduce with aging, while cortisol levels remain substantially unchanged, resulting in an overall increase in the cortisol:DHEA ratio. These hormonal changes are significant in the context of RACK1 expression and signaling function because DHEA administration in vivo and in vitro can restore the levels of RACK1 and the function of the PKC signaling cascade in aged animals and in human cells. In contrast, there is evidence that cortisol can act as a negative transcriptional regulator of RACK1 expression. The rack1 gene promoter contains a glucocorticoid responsive element that is also involved in androgen signaling. Furthermore DHEA may have an indirect influence on the post-transcriptional regulation of the functions of the glucocorticoid receptor. In this review, we will examine the role of the hormonal regulation of rack1 gene transcriptional regulation and the consequences on signaling and function in immune cells and immunosenescence.
\end{abstract}

Keywords: aging; immunosenescence; signal transduction; protein kinase C; transcriptional regulation; cortisol; dehydroepiandrosterone; glucocorticoid receptors.

\section{Introduction}

One of the most acknowledged consequences of aging is the reduced effectiveness of the immune system, which shows profound and age-dependent changes in the response to immunological challenges. The age-dependent decrease in immunological competence results from the progressive deterioration of both innate and adaptive immune responses [1]. Many factors contribute to this phenomenon, including stem-cell defects, thymic involution, aging of resting immune cells, replicative senescence of clonally expanding cells because of the erosion of telomere ends, defects in antigen-presenting cells, dysfunction in several signal transduction pathways, and dysregulation of 
the cytokine network [2]. Among these, the age-dependent decline of immune functions can be, at least in part, correlated with defective protein kinase C (PKC) signal transduction, which can be ascribed to the reduced expression of the Receptor for Activated C Kinase 1 (RACK1), a scaffold protein for different kinases and membrane receptors [3].

RACK1 binds activated PKC $\beta I I$ in order to stabilize its active conformation [4] and promote its translocation close to specific PKC $\beta$ II substrates essential for immune cell activation, proliferation, differentiation, and survival [5]. We and others ([6] and refs within) have demonstrated that PKC $\beta$ II activation plays a key role in the inflammatory response by inducing TNF- $\alpha$ release. An age-associated decrease in the release of TNF- $\alpha$ after lipopolysaccharide (LPS) stimulation was initially observed in alveolar macrophages obtained from aged rats, which produced $\sim 50 \%$ less TNF- $\alpha$ than those from young rats [6]. A similar observation was also reported in human monocytes/macrophages, as well as in peripheral blood leukocytes, and was attributed to deficient PKC translocation due to an age-dependent decline in RACK1 expression [7,8]. As a consequence of the signal transduction impairment, a significant decrease in immune function, including the response to influenza vaccination [8], cell proliferation, and cytokine production was observed $[6,7,9,10]$. Interestingly, the same defective PKC signaling was also observed in the brain of aging animals, and it was demonstrated to be central in the impairment of memory processes [11-13].

The decrease in RACK1 expression is correlated with reduced secretion of dehydroepiandrosterone (DHEA) during aging [7]. Blood levels of DHEA are age-dependent and increase throughout childhood and puberty. After the age of 30, they decrease until reaching a minimum after the age of 80 [14]. This aspect is particularly relevant for the PKC signaling pathway because, in aged animals and in human cells, DHEA administration in vitro and in vivo can restore RACK1 levels, thus re-establishing a dose dependent TNF- $\alpha$ release after LPS stimulation [7,9]. Hence, part of the defective signaling in immune cells can be ascribed to age-related alteration of the hormonal balance.

This finding is particularly significant considering that cortisol levels remain substantially unchanged throughout an individual's life, resulting in an overall increase in the cortisol:DHEA ratio [8]. This increase leads to an imbalance between the actions of these hormones, impairing the ability of DHEA to counter the effect of cortisol [15]. Cortisol acts as a negative regulator of RACK1, while DHEA inhibits cortisol activity, thereby promoting RACK1 expression [16]. The opposing effects of cortisol and DHEA seem to be derived, at least in part, from a complex influence on the post-transcriptional regulation of the glucocorticoid receptor (GR) $[17,18]$.

These considerations underline the importance of exploring the role of RACK1 in the context of immunosenescence and the current knowledge of the mechanisms supporting the role of cortisol and DHEA in the regulation of RACK1 expression.

\section{The Critical Involvement of Hormonal Balance Affecting RACK1 Expression}

The endocrine system plays an important role in modulating immune function, and it is well established that the aging process is accompanied by hormonal changes characterized by an imbalance between catabolic hormones that remain stable and anabolic hormones such as DHEA that decrease with age [19]. In the elderly, a common observation is an imbalance between cortisol and DHEA, with an increase in the cortisol:DHEA ratio, mainly due to a significant reduction in the levels of DHEA [14,19].

Glucocorticoids have a wide spectrum of biological functions, which include stress resistance, the regulation of gluconeogenesis, cell proliferation, control of inflammation, and immune responses. Particularly relevant is the last property, which allows for their widespread use as therapeutic agents for acute and chronic inflammation, as well as in autoimmune disorders and in the treatment of leukemia and lymphoma [20].

As reviewed by Hazeldine et al. [21], there is significant evidence that DHEA can exert immunomodulatory effects that include the inhibition of glucocorticoid activity. There are some 
concerns about the applicability of rodents as a useful model, as the site of DHEA production in rodents appears to be localized to tissues such as the brain rather than in the adrenal glands, as is the case in humans. Nevertheless, studies in humans and human derived cells have demonstrated the role of DHEA in regulating human immunity $([7,8]$, reviewed in [21]). Although the clinical data, derived from the attempted modulation of the immune function with DHEA supplementation, is conflicting, there is still interest in the potential role of this steroid hormone in age-related immunosenescence, provided that its mechanism of action is properly elucidated.

The evidence that DHEA exerts anti-glucocorticoid properties on RACK1 is consistent with an antagonistic paradigm. For example, it has been demonstrated that RACK1 down-regulation caused by physiological cortisol concentrations $(0.1$ and $0.5 \mu \mathrm{M})$ could be counterbalanced by pre-treatment with physiological $(10 \mathrm{nM})$ and pharmacological $(100 \mathrm{nM})$ concentrations of DHEA. The most effective time of pre-incubation was $72 \mathrm{~h}$, although significant effects could be demonstrated also at $16 \mathrm{~h}$. The effect of DHEA was observed on the promoter activity, on the mRNA levels, and at protein level. The interaction between DHEA and cortisol on RACK1 was also tested in the context of a functional immune response, wherein THP- 1 cells were treated with LPS in order to induce TNF- $\alpha$ release, and, as expected, pre-treatment with DHEA reduced the inhibitory effect of cortisol on LPS-induced TNF- $\alpha$ release [16].

The effect of cortisol on RACK1 expression is clearly transcriptional, and the experimental evidence suggests that the effect of DHEA on RACK1 is similarly transcriptional in nature. However, there is no clear indication of the interaction of DHEA with a nuclear receptor with canonical transcriptional activity. As the contrasting effect of DHEA on RACK1 expression cannot be explained by a direct interaction on the promoter region or with simple pharmacological antagonism, a number of different indirect mechanisms have been explored (Reviewed in [22]).

\section{RACK1 and Its Transcriptional Regulation}

\subsection{RACK1: A Versatile Hub of Different Signaling Pathways}

The human rack 1 gene is mapped to chromosome $5 \mathrm{q} 35.3$ in close proximity to the telomere of chromosome 5. The open reading frame of the gene is $1142 \mathrm{bp}$, and it encodes for a protein with 317 amino acids, registering as a $36 \mathrm{kDa}$ protein on Sodium Docecyl Sulfate Polyacrylamide Gel Electrophoresis (SDS PAGE) gel [23,24]. RACK1 belongs to the tryptophan-aspartate repeat family (WD-repeat). It is homologous to the $\beta$ subunit of G-protein $(G \beta)$, the best-characterized WD repeat protein, and contains a seven-bladed $\beta$-propeller structure that serves as a docking site for interacting proteins [3].

RACK1 was first identified in a rat brain cDNA library screen designed to isolate anchor proteins that bound PKC in the presence of its activators, diacylglycerol, calcium, and phosphatidylserine [25-27]. The binding of RACK1 to promote signaling via PKC has been characterized for specific isoforms, including PKC $\beta I I$ [5], PKC $\delta$ [28], and PKC $\mu$ [29]. The extensive investigation of the relationship between RACK1 and its binding partners has led to the realization that RACK1 interacts with numerous proteins (mostly engaged in signaling), either directly or as a part of a larger complex in distinct cellular compartments [3,30]. Some of the signaling partners include Mitogen Activated Protein Kinase (MAPK), Jun-N-terminal Kinase (JNK), and cAMP specific phosphodiesterase PDE4D5, as well as Src kinase and integrins [22,31-33]. The functions supported by these interactions range from cell growth and survival to cell mobility and suggest a potential role for RACK1 in the development and spread of cancerous cells. The specific role of RACK1 in these aspects is, however, still controversial and appears to be cell, context, and stimulus dependent (see $[31,34]$ for a review).

RACK1 has also been implicated as a ribosomal protein [35,36], suggesting an alternate mechanism via which this protein can alter gene translation and signal transduction. RACK1 is part of the small ribosomal subunit and promotes translation via the recruitment of PKC and the phosphorylation of the 
eIF6. In some types of cancers, RACK1's function as ribosomal protein can promote the proliferation and survival of neoplastic cells [34]

Although much is known about RACK1 protein localization, interactions, and related functions, the mechanisms regulating its expression remain relatively unexplored.

\subsection{The RACK1 Promoter Element and Its Transcription Factor Binding Sites}

A bioinformatics analysis on the porcine rack1 gene promoter identified a serum responsive element (SRE) controlling gene expression. In porcine cells, it was observed that RACK1 protein was transiently induced by serum growth factors. Similarly, RACK1 expression was positively stimulated by phorbol esters through the mediation of the AP1 binding site. Moreover, a site for the Nuclear Factor- $\mathrm{kB}(\mathrm{NF}-\mathrm{kB}) / \mathrm{c}-$ rel transcription factor was identified [37] and later mapped in a mouse promoter, where it demonstrated a fundamental role in the regulation of RACK1 expression [38].

The promoter of the human rack1-encoding gene, previously described in DNA databases as guanine nucleotide binding protein $\beta$ polypeptide 2-like 1 (GNB2L1), was studied by cloning a $2-\mathrm{kb}$ region $5^{\prime}$ of the rack1 human gene [20]. Analysis in silico suggested the presence of several binding sites for transcription factors and two major transcription start sites (TSS), similar to what was observed in the mouse gene [20,38]. Binding sites for transcription factors belonging to a smooth muscle/cardiomyocyte specific family were recognized. Consensus binding sites for Hand1/E47, Elk-1, and Nkx2-5, which are cardiac specific homeobox, and myogenin/NF1 factor, which is involved in muscle differentiation and growth, were specifically identified.

Similar to those found in the mouse and porcine genes, four c-Rel binding sites were identified in the human RACK1 promoter [24]. c-Rel is a member of the NF- $\mathrm{KB}$ transcription factor family, which has been demonstrated to have a role in neuronal plasticity and survival $[39,40]$. In SH-SY5Y human neuroblastoma cells, sAPP $\alpha$, a soluble amyloid precursor protein (APP) fragment secreted in conditioned medium of cultured cells, human plasma, and the cerebrospinal fluid, could modulate the expression of RACK1 and the signaling activity of PKC $\beta$ II through the activation of the PI3K/Akt and NF- $\mathrm{B}$ pathways. sAPP $\alpha$ treatment induced c-Rel nuclear translocation, favoring its binding to the RACK1 promoter, which correlated with an increase in RACK1 expression [13]. These observations are particularly relevant in the context of Alzheimer's disease (AD), wherein RACK1 levels have been found to be significantly decreased in both membrane and cytosolic fractions obtained from AD brains when compared to age and post mortem matched control cases, suggesting a role for RACK1 expression in cognitive degeneration and age related conditions [41,42].

NF- $\mathrm{KB}$ involvement in RACK1 regulation was also demonstrated in cells of neural and immune origin using two well-known stimuli; LPS, an immune stimulus, and phorbol 12-myristate 13-acetate (PMA), a direct activator of the PKC pathway, which was previously reported to induce RACK1 protein expression [37]. Both molecules are linked, directly or indirectly, to nuclear cellular signals by means of the NF- $\mathrm{KB}$ pathway. The treatment of THP-1 (human monocytic cell line) and SH-SY5Y cells with either LPS or PMA resulted in a significant increase in RACK1 expression [24].

In addition, Oct-1, Elk-1, and Pax-4 transcription factor binding sites were also identified. Finally, a consensus sequence for the binding of GR (Glucocorticoid Receptor), which appears to be similar to the consensus for a negative glucocorticoid responsive element (GRE) or nGRE, was detected at nucleotide -186 ( +1 is the first TSS) [24]. nGRE binding is a new mode of sequence recognition for the human GR; two GR monomers bind nGREs in an inverted repeat orientation with strong negative cooperativity, which mediates DNA-dependent transrepression. The ability to repress to the GR at nGRE sites may allow targeted immunosuppressive therapy without the side effects often observed with glucocorticoid treatment [43]. (Figure 1). 

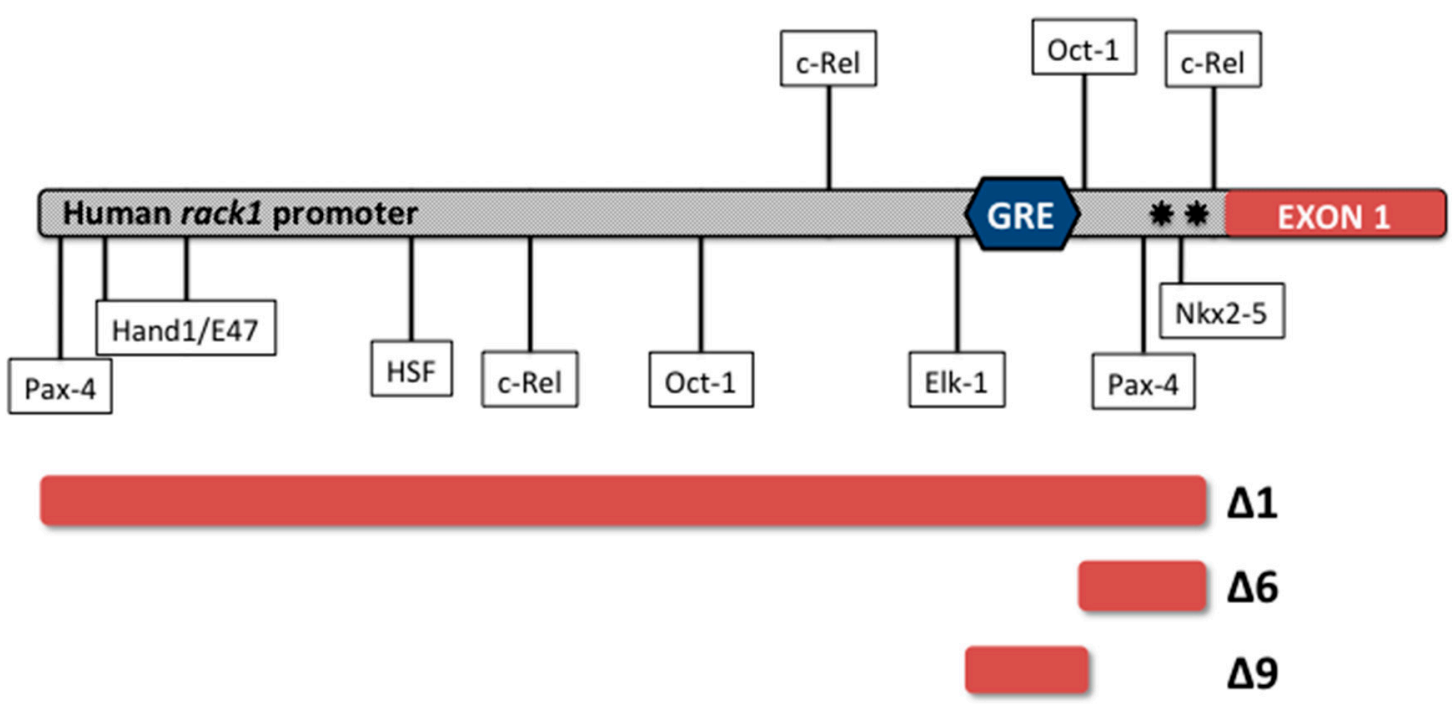

Figure 1. Structural analysis of the human receptor for activated C kinase 1 (RACK1) gene promoter region. Bioinformatic analysis of the $5^{\prime}$-flanking region within $7 \mathrm{~kb}$ upstream of the putative promoter region of the human rack1 gene identified two major transcription sites, which are indicated with stars just before the beginning of Exon 1. Several putative cis-acting elements are shown; in particular, the putative unique GRE (Glucocorticoid Responsive Element) is detected at the nucleotidic position -186 with the sequence AGAACACCCTCCGGAAGCACA. Functional characterization of the GRE site was performed with deletion constructs $(\Delta 1, \Delta 6$, and $\Delta 9)$, including or excluding the GRE site. More details can be found in the text and in $[16,24]$.

\subsection{RACK1 and Its Glucocorticoid Regulation}

The discovery of the putative nGRE consensus sequence on the rack1 gene promoter led to an investigation of the role of glucocorticoids in the regulation of RACK1 expression. Preliminary analyses performed in SH-SY5Y cells showed a significant repression of the activity of the rack1 gene promoter following $24 \mathrm{~h}$ of treatment with $1 \mu \mathrm{M}$ of cortisol [24]. A more detailed analysis of the role of the GRE element in controlling the RACK1 promoter was conducted in THP-1 cells transiently transfected with three luciferase reporter constructs; $\Delta 1, \Delta 6$, and $\Delta 9$ [16]. The $\Delta 1$ luciferase reporter construct represented the entire 2-kb region $5^{\prime}$ of the human rack1 gene [24], whereas the construct $\Delta 6$ was a promoter fragment only that did not include the GRE sequence; the $\Delta 9$ construct included only the GRE sequence. THP-1 cells were transfected with these reporter constructs and treated with two physiological cortisol concentrations, $0.1 \mu \mathrm{M}$ and $0.5 \mu \mathrm{M}$, which were chosen as they are representative of the most common range of the total plasma concentration of cortisol in humans. These studies demonstrated that in the presence of promoter constructs bearing the putative GCs responsive element cortisol induced a significant down-regulation of luciferase activity. In line with this evidence, cortisol was also able to drastically reduce RACK1 expression at both the mRNA and protein level, with a decline of about $70-80 \%$ compared to control cells. Additional support for a direct effect of cortisol on the promoter region of RACK1 comes from later observations that the potent GR antagonist mifepristone or RU486 abolished the cortisol-induced inhibition of luciferase activity, preventing RACK1 down-regulation [44], while the GR binding to the GRE sequence was demonstrated by ELISA based transcription factor binding assay [17]. Further evidence suggests that other corticosteroids such as betamethasone, budesonide, methylprednisolone, prednisone, and prednisolone can also target RACK1. The most effective inhibitors of LPS-induced cytokine release, namely budesonide, betamethasone, and methylprednisolone, were also most effective in reducing RACK1 mRNA expression and protein levels, thus confirming a correlation between RACK1 expression and the level of cytokine released in response to LPS. Finally, the importance of RACK1 modulation in the anti-inflammatory effect of cortisol was demonstrated using a RACK1 pseudosubstrate, which 
directly activates PKC $\beta$. Cortisol inhibition of LPS-induced cytokine release was prevented when RACK1 pseudosubstrate was added together with LPS [45], suggesting that RACK1 expression is central to the anti-inflammatory effect of cortisol. Synthetic glucocorticoid recapitulated these results [44], supporting the notion that RACK1 protein is an important target of corticosteroid-induced anti-inflammatory effects. RACK1 can therefore be considered a novel transcriptional target of corticosteroid-induced anti-inflammatory effects.

\section{DHEA and Cortisol in the Regulation of GR Isoforms}

The human gene NR3C1, which encodes the GR, is composed of nine exons. Alternative splicing in exon 9 generates two homologous receptor isoforms, termed GR $\alpha$ and GR $\beta[46,47]$. GR $\alpha$ mediates most of the known glucocorticoid actions, while the GR $\beta$ isoform is expressed in most tissues but lacks the ligand-binding domain. As a result, GR $\beta$ does not bind glucocorticoids and thus is unable to activate glucocorticoid-responsive gene promoters [48-50]. Indeed, there is evidence that GR $\beta$ acts as a dominant negative of GR $\alpha$ [50,51]. In the context of RACK1 expression, the presence of the GR $\beta$ /GR $\alpha$ inactive complex on a GRE site was demonstrated by transcription factor binding assay. When THP- 1 cells were treated for 16-18 h with DHEA (10 and $100 \mathrm{nM})$ and then stimulated with cortisol $(0.1$ and $0.5 \mu \mathrm{M})$, a significant increase in the GR $\beta / G R \alpha$ binding ratio was observed [17]. Hence, DHEA induces the increase of GR $\beta /$ GR $\alpha$ complex by GR $\beta$ up-regulation and counteracts the cortisol-induced binding of GR $\alpha$ to the RACK1 promoter region, thus reinforcing the idea that GR $\beta$ is a dominant-negative regulator of GR $\alpha$ activity [17]. Further investigation into the mechanism of action of DHEA in the context of GR splicing showed that DHEA induced the up-regulation of total GR mRNA, which was preferentially directed toward the $\beta$ isoform, by increasing expression of the splicing factor SRSF9 (Serine/arginine Rich Splicing Factors 9), also known as SRp20 [18].

As discussed in Section 2, DHEA can modulate RACK1 protein levels via a transcriptional mechanism that does not involve a direct interaction with the promoter region of the rack 1 gene, and hence it can partially act by GR $\beta$ modulation. In line with these considerations, it was demonstrated that GR $\beta$ knockdown completely prevented DHEA-induced RACK1 expression and the modulation of cytokine release, highlighting that the effect of DHEA is driven by a modulation of GR $\beta$ expression and activity [17]. DHEA involvement in GR $\beta$ expression was confirmed by SRSF9 silencing; SRSF9 knockdown completely blocked the increase of GR $\beta$ induced by DHEA with a consequent prevention of DHEA-induced RACK1 expression [18]. These results suggest that the effect of DHEA is driven by a modulation of SRSF9, which, in turn, influences GR $\beta$ expression and activity, thus reinforcing the idea that GR $\beta$ is a dominant-negative regulator of GR $\alpha$ activity.

In contrast, cortisol specifically exerted a shift in the pattern of expression of the GR, promoting the $\alpha$ isoform at the expense of GR $\beta$. Hence, cortisol did not affect the total GR mRNA levels, but it influenced and controlled the exon inclusion and exclusion in GR mRNA transcript by modulating, in an opposite way, SRSF3 (also known as SRp30c) and SRSF9 expression, which are two splicing factors involved in GR alternative splicing. Cortisol up-regulated SRSF3, the GR $\alpha$ promoting splicing factor, and down-regulated SRSF9. Moreover, cortisol-induced GR $\alpha$ expression was correlated with RACK1 down-regulation. In fact, SRSF3 silencing prevented the inhibitory effect of cortisol on RACK1 expression levels [18].

These data suggest that cortisol and DHEA can influence the alternative splicing of GR and underline the necessity of a critical balance between these serine/arginine-rich proteins to control the level of exon inclusion/exclusion in the mRNA transcript. Finally, these data also support the idea that the anti-glucocorticoid effect of DHEA, among other mechanisms, is also exerted by the modulation of the expression of proteins involved in the splicing of the GR pre-mRNA.

It is also worthwhile to note that the effect of DHEA on RACK1 expression could be completely prevented by using flutamide, an androgen receptor (AR) antagonist. It was demonstrated that flutamide prevented DHEA induced GR $\beta$ protein expression [52] In line with this result, 
DHEA-induced total GR mRNA expression was also prevented by flutamide treatment [18], according to recent evidence demonstrating an androgen response element upstream of the GR gene.

\section{Effect of Androgens in DHEA-Induced RACK1 Expression}

The physiological actions of DHEA have been attributed to its conversion to either androgens or estrogens. Recent data indicates that both THP-1 and human peripheral blood mononuclear cells (PBMCs) are able to rapidly convert DHEA to dihydrotestosterone (DHT). Hence, the ability of testosterone, DHT, and androstenedione to induce RACK1 expression and cytokine production was evaluated. As with DHEA, an increase in RACK1 expression and in LPS-induced IL-8 and TNF- $\alpha$ production was observed after treatment with these selected androgens. The role of DHT in DHEA-induced RACK1 expression was also corroborated by the ability of finasteride, a $5 \alpha$-reductase inhibitor, to completely block the effect of DHEA on RACK1 mRNA expression. The key role of the AR to mediate DHEA-induced RACK1 expression was finally confirmed by silencing experiments [52].

Overall, these data, together with the ability of physiologically relevant concentrations of testosterone and DHT to induce RACK1 expression, support the notion that the metabolic transformation of DHEA to androgens and their binding to the AR are required for DHEA-induced RACK1 expression and cell activation.

It is important to note that approximately one-half of the AR cistrome overlaps with that of the GR. Indeed, the DNA-binding domain (DBD) of class I steroid receptors, including the AR, GR, progesterone receptor (PR), and mineralocorticoid receptor (MR), is highly conserved. All recognize a response element usually described as a canonical androgen/glucocorticoid response element (ARE/GRE) and are characterized by a well-conserved $5^{\prime}$-hexamer ( $5^{\prime}$-AGAACA- $3^{\prime}$ ) and a less stringent sequence requirement for the $3^{\prime}$-hexamer [53]. In fact, different spacer-lengths or different hexamer-orientations have been proposed [54,55]. Therefore, the non-canonical GRE sequence described in the rack1 gene promoter may also be considered as a cis-regulatory target of the AR, as it consists of direct repeats of the sequence 5'-AGAACAccctccggaAGCACA-3'.

In this context, and to further support the role of AR in RACK1 expression, recent data suggested a direct involvement of the AR in RACK1 regulation mediated by $p, p^{\prime} D D T$ (dichlorodiphenyltrichloroethane) and $\mathrm{p}, \mathrm{p}^{\prime} \mathrm{DDE}$ (dichlorodiphenyldichloroethylene), a weak and a strong AR antagonist, respectively. In THP-1 cells transiently transfected with a luciferase reporter construct of the rack1 gene promoter and incubated with increasing concentrations of $\mathrm{p}, \mathrm{p}^{\prime} \mathrm{DDT}$ and $\mathrm{p}, \mathrm{p}^{\prime} \mathrm{DDE}$, the reporter luciferase activity was strongly reduced by both endocrine disrupting chemicals (EDC), with $\mathrm{p}, \mathrm{p}^{\prime} \mathrm{DDE}$ being more potent than $\mathrm{p}, \mathrm{p}^{\prime} \mathrm{DDT}$. Moreover, the decrease in RACK1 expression was accompanied by a consequent impairment of IL- 8 and TNF $\alpha$ release following LPS stimulation. In contrast, treatment with the AR agonist nandrolone resulted in a dose-related increase in luciferase activity and consequently in RACK1 expression. These findings suggest that RACK1 could be a relevant target of EDCs, responding in an opposing manner to agonists or antagonists of the AR and representing a bridge between the endocrine system and the innate immune system [56].

These last observations should also be considered in the context of RACK1, taking into account that both the AR and GR can interact at the transcriptional level and that this interaction is correlated with their ability to form heterodimers at a common DNA site, both in vitro and in vivo. Moreover, GREs differ in their precise sequence motifs and in the functional GR surfaces required for binding or regulation. In vivo, many genomic regions that contain the GR binding sites consist only of half sites, and these regions are likely responsible for the regulation of a subset of target genes [57]. (Figure 2). 


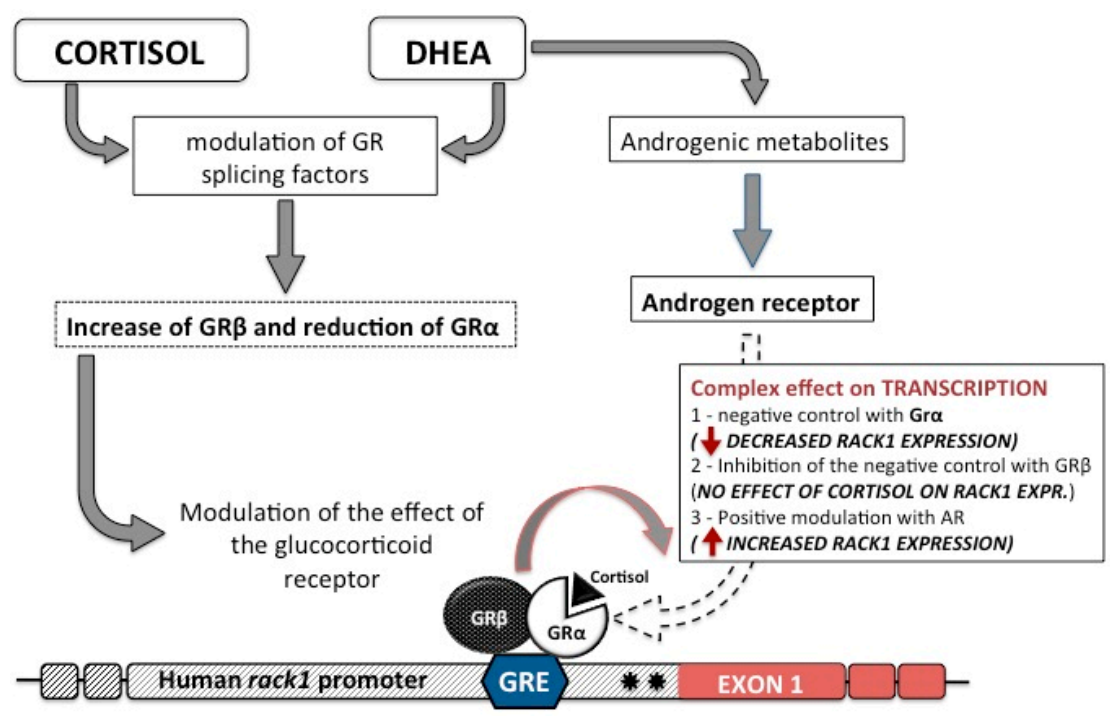

Figure 2. Scheme of the complex hormonal balance in the control of RACK1 expression. Data suggest that cortisol and dehydroepiandrosterone (DHEA) can influence alternative splicing of the GR, controlling the level of exon inclusion/exclusion in the mRNA transcript $[17,18]$, and therefore suggesting that the anti-glucocorticoid effect of DHEA is due, in part, to modulation of the expression of proteins involved in the splicing of the glucocorticoid receptor (GR) pre-mRNA. In addition, the effect of DHEA on RACK1 expression is dependent on its transformation into active androgen steroids [52]. Although pharmacological evidence supports the role of the AR, there is not yet direct demonstration of the interaction of the androgen receptor (AR) with the hormone sensitive site on the rack1 gene promoter; hence the dotted line arrow in the scheme.

\section{Conclusions}

Taken together, these data support the existence of a complex hormonal balance between steroid hormones in the control of immune modulation, which should be further investigated within the context of immunosenescence and endocrinosenescence. A majority of the data points to a role for the cortisol:DHEA ratio in the determination of an appropriate functional response within cells of the immune system during aging. The hormonal imbalance between cortisol and DHEA observed with aging may affect directly the signal transduction cascade involved in the normal functions of key players of the innate immune system. It is therefore critical to understand the molecular mechanism through which cortisol and DHEA regulate RACK1 expression, especially considering the central role of RACK1 in cellular homeostasis. Indeed, changes in RACK1 levels are likely to subvert physiological functions, which go far beyond the immune system, possibly affecting tumor progression as demonstrated by the opposing effects of nandrolone and p, $\mathrm{p}^{\prime} \mathrm{DDE}$ on THP-1 cell proliferation [56].

Acknowledgments: This research has been supported by Ministero dell'Istruzione, dell'Università e della Ricerca (PRIN2009) to M.R. and E.C. We acknowledge the contribution of a Crowdfunding initiative through the Universitiamo Campaign of the University of Pavia and specifically acknowledge the contribution of Fondazione Zoe; Aboca S.p.A.; Microna srl; Sen. Luis Alberto Orellana; M\&M Mediaservices; Magenta Farmaceutici; Massimo Vergnano; Pintotecno srl; Mario Malacrida and Family; Yakult Italia; Mecvel srl; Giovanna Spairani; Labospace srl; Mark Lively; Stefano Govoni; Anna Pinto; Ivana Trentini; and Margherita Villa. Marilisa Galasso is recipient of the 'Nathalie Salvietti fellowship for Aging research'. We are grateful to Dori Germolec for careful reading and editing of the manuscript.

Conflicts of Interest: The authors declare no conflict of interest. 


\section{Abbreviations}

$\begin{array}{ll}\text { RACK1 } & \text { Receptor for Activated C Kinase1 } \\ \text { DHEA } & \text { Dehydroepiandrosterone } \\ \text { PKC } & \text { Protein Kinase C } \\ \text { AD } & \text { Alzheimer's disease } \\ \text { GRE } & \text { Glucocorticoid responsive element } \\ \text { AR } & \text { Androgen receptor } \\ \text { GR } & \text { Glucocorticoid receptor } \\ \text { EDC } & \text { Endocrine disrupting chemicals } \\ \text { LPS } & \text { Lipopolysaccharide }\end{array}$

\section{References}

1. Fülöp, T.; Dupuis, G.; Witkowski, J.M.; Larbi, A. The role of immunosenescence in the development of age-related diseases. Rev. Investig. Clin. 2016, 68, 84-91.

2. Ponnappan, S.; Ponnappan, U. Aging and immune function: Molecular mechanisms to interventions. Antioxid. Redox Signal. 2011, 14, 1551-1585. [CrossRef] [PubMed]

3. Adams, D.R.; Ron, D.; Kiely, P.A. RACK1, a multifaceted scaffolding protein: Structure and function. Cell Commun. Signal. 2011, 9, 22. [CrossRef] [PubMed]

4. Ron, D.; Luo, J.; Mochly-Rosen, D. C2 region-derived peptides inhibit translocation and function of $\beta$ protein kinase C in vivo. J. Biol. Chem. 1995, 270, 24180-24187. [CrossRef] [PubMed]

5. Nishizuka, Y. Protein kinase C and lipid signaling for sustained cellular responses. FASEB J. 1995, 9, 484-496. [PubMed]

6. Corsini, E.; Battaini, F.; Lucchi, L.; Marinovich, M.; Racchi, M.; Govoni, S.; Galli, C.L. A defective protein kinase $\mathrm{C}$ anchoring system underlying age-associated impairment in TNF- $\alpha$ production in rat macrophages. J. Immunol. 1999, 163, 3468-3473. [PubMed]

7. Corsini, E.; Racchi, M.; Sinforiani, E.; Lucchi, L.; Viviani, B.; Rovati, G.E.; Govoni, S.; Galli, C.L. Age-Related decline in RACK1 expression in human leukocytes is correlated to plasma levels of dehydroepiandrosterone. J. Leukoc. Biol. 2005, 77, 247-256. [CrossRef] [PubMed]

8. Corsini, E.; Vismara, L.; Lucchi, L.; Viviani, B.; Govoni, S.; Galli, C.L.; Marinovich, M.; Racchi, M. High interleukin-10 production is associated with low antibody response to influenza vaccination in the elderly. J. Leukoc. Biol. 2006, 80, 376-382. [CrossRef] [PubMed]

9. Corsini, E.; Lucchi, L.; Meroni, M.; Racchi, M.; Solerte, B.; Fioravanti, M.; Viviani, B.; Marinovich, M.; Govoni, S.; Galli, C.L. In vivo dehydroepiandrosterone restores age-associated defects in the protein kinase C signal transduction pathway and related functional responses. J. Immunol. 2002, 168, 1753-1758. [CrossRef] [PubMed]

10. Racchi, M.; Sinforiani, E.; Govoni, S.; Marinovich, M.; Galli, C.L.; Corsini, E. RACK1 expression and cytokine production in leukocytes obtained from AD patients. Aging Clin. Exp. Res. 2006, 218, 153-157.

11. Battaini, F.; Pascale, A.; Lucchi, L.; Pasinetti, G.M.; Govoni, S. Protein kinase C anchoring deficit in postmortem brains of Alzheimer's disease patients. Exp. Neurol. 1999, 159, 559-564. [CrossRef] [PubMed]

12. Battaini, F.; Pascale, A.; Paoletti, R.; Govoni, S. The role of anchoring protein RACK-1 in PKC activation in the aging rat brain. Trends Neurosci. 1997, 20, 410-415. [CrossRef]

13. Buoso, E.; Biundo, F.; Lanni, C.; Aiello, S.; Grossi, S.; Schettini, G.; Govoni, S.; Racchi, M. Modulation of RACK1/PKC $\beta I I$ signalling by soluble A $\beta P P \alpha$ in SH-SY5Y cells. Curr. Alzheimer Res. 2013, 10, 697-705. [CrossRef] [PubMed]

14. Maggio, M.; de Vita, F.; Fisichella, A.; Colizzi, E.; Provenzano, S.; Lauretani, F.; Luci, M.; Ceresini, G.; Dall'Aglio, E.; Caffarra, P.; et al. DHEA and cognitive function in the elderly. J. Steroid Biochem. Mol. Biol. 2015, 145, 281-292. [CrossRef] [PubMed]

15. Cravello, L.; Muzzoni, B.; Casarotti, D.; Paltro, M.; Solerte, S.B.; Fioravanti, M.; Cuzzoni, G.; Pontiggia, B.; Magri, F.; Ferrari, E. Age-Related changes of the hypothalamic-pituitary-adrenal axis: Pathophysiological correlates. Eur. J. Endocrinol. 2001, 144, 319-329. 
16. Buoso, E.; Lanni, C.; Molteni, E.; Rousset, F.; Corsini, E.; Racchi, M. Opposing effects of cortisol and dehydroepiandrosteie on the expression of the receptor for Activated C Kinase 1: Implications in immunosenescence. Exp. Gerontol. 2011, 46, 877-883. [CrossRef] [PubMed]

17. Pinto, A.; Malacrida, B.; Oieni, J.; Serafini, M.M.; Davin, A.; Galbiati, V.; Corsini, E.; Racchi, M. DHEA modulates the effect of cortisol on RACK1 expression via interference with the splicing of the glucocorticoid receptor. Br. J. Pharmacol. 2015, 172, 2918-2927. [CrossRef] [PubMed]

18. Buoso, E.; Galasso, M.; Ronfani, M.; Serafini, M.M.; Lanni, C.; Corsini, E.; Racchi, M. Role of spliceosome proteins in the regulation of glucocorticoid receptor isoforms by cortisol and dehydroepiandrosterone. Pharmacol. Res. 2017, 120, 180-187. [CrossRef] [PubMed]

19. Maggio, M.; Cattabiani, C.; Lauretani, F.; Ferrucci, L.M.; Luci, M.; Valenti, G.; Ceda, G. The concept of multiple hormonal dysregulation. Acta Biomed. 2010, 81, 19-29. [PubMed]

20. Bruscoli, S.; Migliorati, G.; Riccardi, C. Molecular mechanisms of immunomodulatory activity of glucocorticoids. Pharmacol. Res. 2002, 45, 361-368.

21. Hazeldine, J.; Arlt, W.; Lord, J.M. Dehydroepiandrosterone as a regulator of immune cell function. J. Steroid Biochem. Mol. Biol. 2010, 120, 127-136. [CrossRef] [PubMed]

22. Buoso, E.; Galasso, M.; Serafini, M.M.; Ronfani, M.; Lanni, C.; Corsini, E.; Racchi, M. Transcriptional regulation of RACK1 and modulation of its expression: Role of steroid hormones and significance in health and aging. Cell Signal. 2017, 35, 264-271. [CrossRef] [PubMed]

23. Wang, S.; Chen, J.Z.; Zhang, Z.; Gu, S.; Ji, C.; Tang, R.; Ying, K.; Xie, Y.; Mao, Y. Cloning, expression and genomic structure of a novel human GNB2L1 gene, which encodes a receptor of activated protein kinase C (RACK). Mol. Biol. Rep. 2003, 30, 53-60. [CrossRef] [PubMed]

24. Del Vecchio, I.; Zuccotti, A.; Pisano, F.; Canneva, F.; Lenzken, S.C.; Rousset, F.; Corsini, E.; Govoni, S.; Racchi, M. Functional mapping of the promoter region of the GNB2L1 human gene coding for RACK1 scaffold protein. Gene 2009, 430, 17-29. [CrossRef] [PubMed]

25. Mochly-Rosen, D.; Khaner, H.; Lopez, J. Identification of intracellular receptor proteins for activated protein kinase C. Proc. Natl. Acad. Sci. USA 1991, 88, 3997-4000. [CrossRef] [PubMed]

26. Mochly-Rosen, D.; Smith, B.L.; Chen, C.H.; Disatnik, M.H.; Ron, D. Interaction of protein kinase C with RACK1, a receptor for activated C-kinase: A role in $\beta$ protein kinase $C$ mediated signal transduction. Biochem. Soc. Trans. 1995, 23, 596-600. [CrossRef] [PubMed]

27. Ron, D.; Mochly-Rosen, D. Agonists and antagonists of protein kinase $C$ function, derived from its binding proteins. J. Biol. Chem. 1994, 269, 21395-21398. [PubMed]

28. Rosdahl, J.A.; Mourton, T.L.; Brady-Kalnay, S.M. Protein kinase C $\delta(\mathrm{PKC} \delta$ ) is required for protein tyrosine phosphatase mu (PTPmu)-dependent neurite outgrowth. Mol. Cell. Neurosci. 2002, 19, 292-306. [CrossRef] [PubMed]

29. Hermanto, U.; Zong, C.S.; Li, W.; Wang, L.H. RACK1, an insulin-like growth factor I (IGF-I) receptor-interacting protein, modulates IGF-I-dependent integrin signaling and promotes cell spreading and contact with extracellular matrix. Mol. Cell. Biol. 2002, 22, 2345-2365. [CrossRef] [PubMed]

30. McCahill, A.; Warwicker, J.; Bolger, G.B.; Houslay, M.D.; Yarwood, S.J. The RACK1 scaffold protein: A dynamic cog in cell response mechanisms. Mol. Pharmacol. 2002, 62, 1261-1273. [CrossRef] [PubMed]

31. Gandin, V.; Senft, D.; Topisiovic, I.; Ronai, Z.A. RACK1 function in cell motility and protein synthesis. Genes Cancer 2013, 4, 369-377. [CrossRef] [PubMed]

32. Liliental, J.; Chang, D.D. RACK1, a receptor for activated protein kinase $C$, interacts with integrin $\beta$ subunit. J. Biol. Chem. 1998, 273, 2379-2383. [CrossRef] [PubMed]

33. Buensuceso, C.S.; Woodside, D.; Huff, J.L.; Plopper, G.E.; O’Toole, T.E. The WD protein RACK1 mediates protein kinase C and integrin-dependent cell migration. J. Cell Sci. 2001, 114, 1691-1698. [PubMed]

34. Li, J.J.; Xie, D. RACK1, a versatile hub in cancer. Oncogene 2015, 34, 1890-1898. [CrossRef] [PubMed]

35. Nilsson, J.; Sengupta, J.; Frank, J.; Nissen, P. Regulation of eukaryotic translation by the RACK1 protein: A platform for signalling molecules on the ribosome. EMBO Rep. 2004, 5, 1137-1141. [CrossRef] [PubMed]

36. Ceci, M.; Gaviraghi, C.; Gorrini, C.; Sala, L.A.; Offenhäuser, N.; Marchisio, P.C.; Biffo, S. Release of eIF6 (p27 ${ }^{\mathrm{BBP}}$ ) from the $60 \mathrm{~S}$ subunit allows $80 \mathrm{~S}$ ribosome assembly. Nature 2003, 426, 579-584. [CrossRef] [PubMed]

37. Chou, Y.C.; Chou, C.C.; Chen, Y.K.; Tsai, S.; Hsieh, F.M.; Liu, H.J.; Hseu, T.H. Structure and genomic organization of porcine rack1 gene. Biochim. Biophys. Acta 1999, 1489, 315-322. [CrossRef] 
38. Choi, D.S.; Young, H.; McMahon, T.; Wang, D.; Messing, R.O. The mouse rack1 gene is regulated by NF- $\mathrm{BB}$ and contributes to cell survival. Mol. Pharmacol. 2003, 64, 1541-1548. [CrossRef] [PubMed]

39. Mattson, M.P.; Camandola, S. NF-кB in neuronal plasticity and neurodegenerative disorders. J. Clin. Investig. 2001, 107, 247-254. [CrossRef] [PubMed]

40. Mattson, M.P. NF-kB in the survival and plasticity of neurons. Neurochem. Res. 2005, 30, 883-893. [CrossRef] [PubMed]

41. Govoni, S.; Amadio, M.; Battaini, F.; Pascale, A. Senescence of the brain: Focus on cognitive kinases. Curr. Pharm. Des. 2010, 16, 660-671. [CrossRef] [PubMed]

42. Racchi, M.; Govoni, S.; Solerte, S.B.; Galli, C.L.; Corsini, E. Dehydroepiandrosterone and the relationship with aging and memory: A possible link with protein kinase $C$ functional machinery. Brain Res. Rev. 2001, 37, 287-293. [CrossRef]

43. Hudson, W.H.; Youn, C.; Ortlund, E.A. The structural basis of direct glucocorticoid-mediated transrepression. Nat. Struct. Mol. Biol. 2013, 20, 53-58. [CrossRef] [PubMed]

44. Corsini, E.; Pinto, A.; Galbiati, V.; Viviani, B.; Galli, C.L.; Marinovich, M.; Racchi, M. Corticosteroids modulate the expression of the PKC-anchoring protein RACK1 and cytokine release in THP-1 cells. Pharmacol. Res. 2014, 81, 10-16. [CrossRef] [PubMed]

45. Corsini, E.; Galbiati, V.; Esser, P.R.; Pinto, A.; Racchi, M.; Marinovich, M.; Martin, S.F.; Galli, C.L. Role of PKC- $\beta$ in chemical allergen-induced CD86 expression and IL-8 release in THP-1 cells. Arch. Toxicol. 2014, 88, 415-424. [CrossRef] [PubMed]

46. Evans, R.M. The steroid and thyroid hormone receptor superfamily. Science 1988, 240, 889-895. [CrossRef] [PubMed]

47. Oakley, R.H.; Sar, M.; Cidlowski, J.A. The human glucocorticoid receptor $\beta$ isoform. Expression, biochemical properties and putative function. J. Biol. Chem. 1996, 271, 9550-9559. [CrossRef] [PubMed]

48. Kino, T.; Su, Y.A.; Chrousos, G.P. Human glucocorticoid receptor isoform: Recent understanding of its potential implications in physiology and pathophysiology. Cell. Mol. Life Sci. 2009, 66, 3435-3448. [CrossRef] [PubMed]

49. Nicolaides, N.C.; Galata, Z.; Kino, T.; Chrousos, G.P.; Charmandari, E. The human glucocorticoid receptor: Molecular basis of biologic function. Steroids 2010, 75, 1-12. [CrossRef] [PubMed]

50. Bamberger, C.M.; Bamberger, A.M.; de Castro, M.; Chrousos, G.P. Glucocorticoid receptor $\beta$, a potential endogenous inhibitor of glucocorticoid action in humans. J. Clin. Investig. 1995, 95, 2435-2441. [CrossRef] [PubMed]

51. Charmandari, E.; Chrousos, G.P.; Ichijo, T.; Bhattacharyya, N.; Vottero, A.; Souvatzoglou, E.; Kino, T. The human glucocorticoid receptor (hGR) $\beta$ isoform suppresses the transcriptional activity of hGR $\alpha$ by interfering with formation of active coactivator complexes. Mol. Endocrinol. 2005, 19, 52-64. [CrossRef] [PubMed]

52. Corsini, E.; Galbiati, V.; Papale, A.; Kummer, E.; Pinto, A.; Serafini, M.M.; Guaita, A.; Spezzano, R.; Caruso, D.; Marinovich, M.; et al. Role of androgens in dhea-induced RACK1 expression and cytokine modulation in monocytes. Immun. Ageing 2016, 13, 20. [CrossRef] [PubMed]

53. Mangelsdorf, D.J.; Thummel, C.; Beato, M.; Herrlich, P.; Schütz, G.; Umesono, K.; Blumberg, B.; Kastner, P.; Mark, M.; Chambon, P.; et al. The nuclear receptor superfamily: The second decade. Cell 1995, 83, 835-839. [CrossRef]

54. Massie, C.E.; Adryan, B.; Barbosa-Morais, N.L.; Lynch, A.G.; Tran, M.G.; Neal, D.E.; Mills, I.G. New androgen receptor genomic targets show an interaction with the ETS1 transcription factor. EMBO Rep. 2007, 8, 871-878. [CrossRef] [PubMed]

55. Wang, Q.; Li, W.; Liu, X.S.; Carroll, J.S.; Jänne, O.A.; Keeton, E.K.; Chinnaiyan, A.M.; Pienta, K.J.; Brown, M. A hierarchical network of transcription factors governs androgen receptor-dependent prostate cancer growth. Mol. Cell 2007, 27, 380-392. [CrossRef] [PubMed] 
56. Buoso, E.; Galasso, M.; Ronfani, M.; Papale, A.; Galbiati, V.; Eberini, I.; Marinovich, M.; Racchi, M.; Corsini, E. The scaffold protein RACK1 is a target of endocrine disrupting chemicals (EDCs) with important implication in immunity. Toxicol. Appl. Pharmacol. 2017, 325, 37-47. [CrossRef] [PubMed]

57. Schiller, B.J.; Chodankar, R.; Watson, L.C.; Stallcup, M.R.; Yamamoto, K.R. Glucocorticoid receptor binds half sites as a monomer and regulates specific target genes. Genome Biol. 2014, 15, 418. [CrossRef] [PubMed]

(C) 2017 by the authors. Licensee MDPI, Basel, Switzerland. This article is an open access article distributed under the terms and conditions of the Creative Commons Attribution (CC BY) license (http:/ / creativecommons.org/licenses/by/4.0/). 